\title{
Effects of Horticultural Therapy on the Emotions and Stress Index of Trainees Entrusted to the Juvenile Classification Review Center
}

\author{
Ja Yeong Ryu ${ }^{1}$, Suk Young Yun ${ }^{2 *}$, and Byung Jin $\mathrm{Choi}^{2}$ \\ ${ }^{1}$ Doctoral Program in Horticulture, Daegu Catholic University, Gyeongsan 38430, Korea \\ ${ }^{2}$ Professor, Department of Horticulture, Daegu Catholic University, Gyeongsan 38430, Korea
}

\section{ABSTRACT}

This study conducted a horticultural therapy program for trainees entrusted to the Juvenile Classification Review Center in order to fill the educational gap while providing emotional stability during the one-month period of commissioned education. The effects of horticultural therapy were examined by the pretest and posttest changes of the emotional items such as anxiety, self-esteem, self-efficacy and stress index. As the research method, this study used the one-group pretest-posttest experimental design on 16 female trainees of commissioned education staying at the Juvenile Classification Review Center in the juvenile reformatory located in A city. The horticultural therapy program was carried out in four sessions: two on flower arrangement and two on planting. The scores before and after the horticultural therapy program were measured using the Revised Children's Manifest Anxiety Scale (RCMAS) to examine the effects of horticultural therapy on the reduction of anxiety for the adolescents staying in the Juvenile Classification Review Center. The results show that there was significant decrease in the mean of anxiety from $62.5(\mathrm{SD}=6.8)$ to $57.6(\mathrm{SD}=8.1)$ points after the program ( $p=.002)$. There was no significant change in self-esteem, which was $76.9(S D=11.2)$ before the horticultural therapy and $78.3(\mathrm{SD}=8.7)$ after the therapy $(p=.420)$. In self-efficacy, there was no significant change from 72.9 (SD $=10.9$ ) before and $75.1(S D=11.0)$ after horticultural therapy $(p=.178)$. In order to examine the physiological changes in such emotional functions, this study measured the stress index using the uBioMacpa as the tool. The result of the measurement showed that there was a significant change in the mean from $33.8(\mathrm{SD}=2.3)$ before to $31.1(\mathrm{SD}=2.2)$ after the horticultural therapy $(p<.001)$.

Keywords: anxiety, female trainees, physiological change, self-efficacy, self-esteem

\section{Introduction}

Adolescence is the period of transition from child to adult in which there are active physical, emotional, cognitive and moral changes but with imbalance. Due to this imbalance, adolescents are exposed to anxiety and stress and undergo psychological problems and identity crisis due to conflicts between adaptation to reality and self-consciousness, sense of loneliness and alienation, and emotions like confusion, thereby opting for delinquency as a solution (Kim, 2013). This is why their deviation, also known as juvenile delinquency, is emerging as a social problem be- yond just a rite of passage in development or a problem among a small minority (Choi, 2012). It has been reported that anxiety of these juvenile delinquents, self-esteem that is the overall attitude toward their abilities and values, self-efficacy that refers to beliefs and expectations about successful competency in certain situations, and methods to cope with stress are greatly affecting delinquency (Hwang, 2012). Butcher (2000) classified factors into risk factors that have negative effects on adolescents' development and protective factors that have positive effects, and claimed that the latter must be promoted.

The Juvenile Classification Review Center is an organ-

Received: October 12, 2019, Revised: November 12, 2019, Accepted: December 30, 2019

First author: Ja Yeong Ryu, rjy3535@naver.com, (1) https://orcid.org/0000-0001-9678-7642

*Corresponding author: Suk Young Yun, yune1004@cu.ac.kr, (1D) https://orcid.org/0000-0002-5862-0021 
ization for temporary measure before determining a suitable place to protect trainees of commissioned education before the court hearing. The Juvenile Classification Review Center runs alternative education programs focused on prevention of delinquency and redelinquency or indirect social experience for juveniles requested by the judge or prosecutor of the Juvenile Court, students subject to disciplinary action according to the Elementary and Secondary Education Act, and juveniles requested by the school principal. Moreover, it is a place that keeps the trainees of commissioned education under custody, investigates their crimes, and provides optimum guidelines about their treatment (Jang, 2006).

Trainees of commissioned education are blocked from their previous educational environment upon their committal. This severance is being blocked out by not only positive but also negative education, that is, delinquency factors (Jin and Kim, 2007). The trainees of commissioned education are already facing a psychological and environmental crisis that is difficult for them to heal on their own, as well as fear and anxiety over protective disposition during the term of consignment, uncertain situation without knowing the results of disposition, unfamiliar life upon committal, and anxiety over being shut out from their guardians. Accordingly, there is an urgent need for education to increase opportunities for them to receive positive education, promote their emotional stability, and prevent redelinquency.

Therefore, this study carries out horticultural therapy on trainees of commissioned education entrusted to the Juvenile Classification Review Center and provide emotional stability as a protective factor that has positive effects. We examined changes in anxiety, self-esteem, and self-efficacy as emotional items that greatly affect delinquency, and determined the effectiveness of horticultural therapy by measuring the stress index to examine the physiological change of emotional functions.

\section{Research Methods}

\section{Subjects}

The subjects are female trainees of commissioned educa- tion being entrusted to the Juvenile Classification Review Center in the juvenile reformatory located in A city upon the court's decision every week. There was no regular cycle for the subjects, but the trainees who filled out the form of consent after listening to the purpose of research at the point of entering the center participated until they left. The subjects all had different dates of entry, and the number of subjects entered was also inconsistent. Moreover, the trainees that were absent due to their family's visit or interview with their lawyer were excluded. The final cumulative number of subjects that participated in the research was 16 trainees, and their mean age was $15.8(\mathrm{SD}=1.64)$.

\section{Methods}

\section{Program design}

Horticultural activities such as growing plants were effective in reducing anxiety and stress of adolescents (Noh, 2016), and positively improved emotional stability of inmates of juvenile reformatories (Han, 2009). Moreover, horticultural therapy promotes self-efficacy according to achievement, provides an experience of social support, and builds self-trust and positive self (Lee and Nam, 2002), while also improving self-esteem of female inmates of juvenile reformatories (Choi, 2012).

The horticultural therapy program used in this study was designed with reference to programs that can improve emotional stability, self-esteem and self-efficacy by analyzing the results of previous studies on horticultural therapy. Moreover, considering that the subjects cannot move around freely, we designed indoor horticultural activities, and the program was designed to be in four sessions in a month while the subjects were committed.

Even though it was a short-term program with just four sessions, we designed it to have two sessions of floral decoration and two sessions of plant growing. By enabling the subjects to plant and grow plants while enjoying the visual and olfactory effects of flowers, the program was to lower their anxiety and stress, improve self-esteem by exploring themselves and others and finding their strengths, and introducing the completed works and presenting their thoughts, thereby increasing self-efficacy. This study used the onegroup pretest-posttest experimental design verifying the 
pretest-posttest mean difference of the experimental group.

\section{Program implementation}

The program was carried out in four sessions once a week for each trainee entrusted from March 21 to September 12, 2018. In other words, this study applied the four-session program to the subjects being committed to the center for 6 months regardless of the session's order. It was carried out for 110 minutes from 9:40 to 11:30 a.m. every Wednesday.

As previously mentioned, the program was comprised of two sessions on flower arrangement and two sessions on planting. In Session 1, we explained about flowers and basic flower shapes with the topic "Expressing my mind", and had the subjects arrange flowers, after which they introduce their works based on the topic and shared their thoughts. In Session 2, the subjects gave presentations on the topic "My most precious friend" referring to their companion plants by transplanting the plant body. In Session 3 , they gave presentations on the topic "Why I am more beautiful than flowers" with the flowers they arranged and discovered their strengths. In Session 4, they created their own beautiful gardens by making a terrarium, talked about who had been with them and who they want to be with based on the topic "Who would you like to be with?", and inquired into friends related to delinquency. Moreover, they were to take care of the plants they had transplanted during the time they were entrusted to the center (Table 1).

\section{Assessment tools}

In this study, we used the Revised Children's Manifest Anxiety Scale (RCMAS), which is a scale adapted and standardized by Choi and Cho (1990) to determine the emotional effects of horticultural therapy on the trainees of commissioned education entrusted to the Juvenile Classification Review Center, which can be applied to children and adolescents aged 6 to 19. We also used the test adapted and reconstructed by Choi and Jeon (1993) to test self-esteem, and the self-efficacy test by Han (2002) developed by revising the general self-efficacy scale by Cha (1997) to rate self-efficacy. Moreover, we used the uBioMacpa, a medical tool developed by the Korea Institute of Science and Technology, to determine physiological changes of emotional functions. The uBioMacpa can measure vessels (peripheral, capillary vascular age) and stress (heart rate variability, autonomic nerve balance test), etc. by having the subjects put their index finger in a pulse wave device and take a measurement for two-and-a-half minutes. The measurement tool can be installed on a personal computer or mobile device to measure the data changes of individual vessels and cumulative stress. In this study, we used the cumulative stress index in the body by extracting heart rate variability from the pulse waves measured.

\section{Data analysis}

Data was analyzed as follows using the IBM SPSS Program (19.0). We used Cronbach's $\alpha$ for reliability test of the scale by internal consistency, and applied the

Table 1. Horticultural therapy program carried out for this study

\begin{tabular}{|c|c|c|c|}
\hline Session & Program & Plants & Activity topics \\
\hline 1 & Flower arrangement & $\begin{array}{c}\text { Dianthus caryophyllus } \\
\text { Helianthus annuus } \\
\text { Rosa hybrida } \\
\text { Eustoma russelianum }\end{array}$ & Expressing my mind \\
\hline 2 & Transplanting & $\begin{array}{c}\text { Crassula ovata } \\
\text { Podocarpus macrophyllus }\end{array}$ & My most precious friend \\
\hline 3 & Flower arrangement & $\begin{array}{l}\text { Lilium lancifolium } \\
\text { Chrysanthemum morifolium } \\
\text { Freesia hybrida }\end{array}$ & Why I am more beautiful than flowers \\
\hline 4 & Terrarium & $\begin{array}{l}\text { Pachyveria glauca } \\
\text { Crassula cv. Gollum }\end{array}$ & Who would you like to be with? \\
\hline
\end{tabular}


Table 2. Reliability analysis of questionnaire

\begin{tabular}{cccc}
\hline Variable & N & Number of items & Cronbach's $\alpha$ \\
\hline Anxiety scale (RCMAS) & 16 & 37 & 32 \\
Self-esteem & 16 & 23 & .84 \\
Self-efficacy & 16 & .80 & .80 \\
\hline
\end{tabular}

Note. RCMAS = Revised Children's Manifest Anxiety Scale.

Table 3. Results of normality test on collected data

\begin{tabular}{cccccc}
\hline Variable & N & M & SD & $p$ \\
\hline Anxiety scale (RCMAS) & 16 & 60.7 & 6.2 & $809^{\mathrm{NS}}$ & $.874^{\mathrm{NS}}$ \\
Self-esteem & 16 & 67.1 & 6.9 & $.919^{\mathrm{NS}}$ \\
Self-efficacy & 16 & 33.8 & 8.1 & $.037^{*}$ \\
Stress index & 16 & & 2.3 & .3 \\
\hline
\end{tabular}

Note. RCMAS = Revised Children's Manifest Anxiety Scale.

${ }^{\mathrm{NS}}$ Non-significant, ${ }^{*} p<.05$ by Kolmogorov-Smirnov test.

one-sample Kolmogorov-Smirnov test to analyze whether the data of measured samples follow normal distribution. Pretest-posttest changes of anxiety, self-esteem and self-efficacy were analyzed using the paired sample t-test. Pretest-posttest changes of stress index was analyzed using the Wilcoxon signed-rank test.

\section{Results and Discussion}

\section{Reliability analysis}

To assess the emotional items of the subjects, we used the self-report questionnaires of anxiety, self-esteem and self-efficacy. As a result of analyzing reliability of the questionnaires, Cronbach's $\alpha$ of RCMAS was .81, Cronbach's $\alpha$ of self-esteem was .84, and Cronbach's $\alpha$ of self-efficacy was .80 (Table 2). Based on the assessment that Cronbach's $\alpha$ of .8 and higher is desirable and .7 and higher is acceptable, the results above can be considered reliable (Lee and Lim, 2015).

\section{Normality test}

We used the one-sample Kolmogorov-Smirnov test to examine whether the data of measured samples follow normal distribution. Anxiety showed normal distribution with $p=.909$ for the mean $60.7(\mathrm{SD}=6.2)$, self-esteem showed normal distribution with $p=.874$ for the mean $67.1(\mathrm{SD}=8.9)$, and self-efficacy showed normal distribution with $p=.919$ for the mean $66.4(\mathrm{SD}=8.1)$. Thus, a parametric test was used to test the mean differences among anxiety, self-esteem and self-efficacy to analyze the effects of horticultural therapy. Stress index did not follow normal distribution with $p=.037$ for the mean 33.8 (SD = 2.3). Thus, the effects of stress index were analyzed using a nonparametric test (Table 3).

\section{Pretest-posttest changes}

To determine the effects of horticultural therapy on emotional changes related to delinquency factors of trainees of commissioned education entrusted to the Juvenile Classification Review Center, we measured anxiety, self-esteem, self-efficacy and stress index before and after the program (Table 4). Anxiety was $62.5(\mathrm{SD}=6.8)$ before horticultural therapy, which decreased significantly to 57.6 $(\mathrm{SD}=8.1)$ after therapy $(p=.002)$. Self-esteem was 76.9 $(\mathrm{SD}=11.2)$ before horticultural therapy, but was 78.3 $(\mathrm{SD}=8.7)$ after, showing no significant change $(p=.420)$. Self-efficacy was 72.9 (SD = 10.9) before horticultural therapy and $75.1(\mathrm{SD}=11.0)$ after, also showing no significant change $(p=.178)$. However, as a result of measuring stress index to determine the physiological changes of 
Table 4. Changes in the anxiety, self-esteem, self-efficacy and stress index of subjects pre and post the implementation of horticultural therapy

\begin{tabular}{|c|c|c|c|c|c|c|}
\hline \multirow{2}{*}{ Variable } & \multirow{2}{*}{ Unit } & \multicolumn{2}{|c|}{ Pre } & \multicolumn{2}{|c|}{ Post } & \multirow{2}{*}{$p$} \\
\hline & & $M$ & SD & M & SD & \\
\hline Anxiety scale (RCMAS) & Score & 62.5 & 6.8 & 57.6 & 8.1 & $.002^{* *}$ \\
\hline Self-esteem & Score & 76.9 & 11.2 & 78.3 & 8.7 & $.420^{\mathrm{NS}}$ \\
\hline Self-efficacy & Score & 72.9 & 10.9 & 75.1 & 11.0 & $.178^{\mathrm{NS}}$ \\
\hline Stress index & - & 33.8 & 2.3 & 31.1 & 2.2 & $<.001^{* * *}$ \\
\hline
\end{tabular}

Note. RCMAS = Revised Children's Manifest Anxiety Scale.

${ }^{\mathrm{NS}}$ Non-significant, ${ }^{* *} p<.01$ by paired t-test, ${ }^{* * *} p<.001$ by Wilcoxon's signed-ranks test.

emotional functions, stress index decreased from 33.8 $(\mathrm{SD}=2.3)$ to $31.1(\mathrm{SD}=2.2)$ after therapy, showing a significant change $(p<.001)$. This result is similar to previous studies proving that a floral design program for female high school students is effective in reducing anxiety and academic stress (Son, 2015), and that $\alpha$ waves for emotional stability increased as a result of brain wave analysis in a space where the subjects were with flowers and plants, and the adolescents on probation who had never been close to flowers could learn the satisfaction of growing something with their own hands and feel a sense of awe toward life by tending flowers (KBS Special Production Team, 2009). In particular, as a result of developing a horticultural therapy program for personality education of inmates of juvenile reformatories and analyzing its effects, the program was proved to bring positive changes to mental maturity, self-esteem, flow and happiness, while also showing effect on physiological change of stress (Choi et al., 2014).

As such, the results were consistent with previous studies in that carrying out a horticultural therapy program for trainees of commissioned education reduces anxiety and stress due to the uncertain disposition results that would be placed on them and the unfamiliar life upon being committed. However, self-esteem and self-efficacy did not show significant results, which is because male students are affected by school life and review of peer groups, whereas female students are affected by the assessment of their relationship with others at school, within family and in their group (Lee and Tak, 2001), and self-efficacy may be promoted by communication with parents and family cohesion including their relationship with the main fosterer, as well as by the feeling as if they are accepted and acknowledged by the group to which they belong (Song, 1996). Accordingly, female trainees of commissioned education have the desire to break free from being the subject of disposition due to the nature of the Juvenile Classification Review Center, rather than being accepted by the group and not freely interacting with other trainees away from their family while being committed.

Horticultural therapy has positive effects on reducing anxiety and stress index of trainees of commissioned education entrusted to the Juvenile Classification Review Center. In other words, the subjects could find emotional stability by watching the plants grow through activities such as transplanting and taking care of plants, express themselves through flower arrangement, explore and share their thoughts according to the topics. In the process, they could reflect on themselves by exploring not only themselves but also their friends. This result is similar to the previous study proving that horticultural therapy increased the power to adapt to the external environment that gives stress to inmates of juvenile reformatories and relieved the psychological aspects of anger, worry and fear (Choi et al., 2016). Therefore, despite the short period, horticultural therapy was effective in promoting emotional stability, while also providing positive educational opportunities. In particular, it promotes emotional stability by adequately coping with anxiety and stress that affect delinquency, and exploring friends related to delinquency will exert positive effects on preventing redelinquency.

This study has limitations in that the dates of entering the Juvenile Classification Review Center varied among the subjects, and the number of subjects entering the center 
was also inconsistent, thereby resulting in only a few cumulative subjects. Moreover, the number of participants was small, since the research excluded trainees who could not participate in training due to reasons such as interviews with the lawyer, visits from parents and various psychological tests in the middle of training. Moreover, the period of committal is just one month, which allowed the subjects to participate only in the four-session program. They also had restrictions in outdoor activities and thus the program was carried out mostly indoors, which is why the effectiveness of outdoor horticultural activities could not be determined. In other words, there were too many environmental constraints, and other educational activities that may give variations to the results could not be controlled, thereby making it difficult to generalize the results of this study.

\section{Conclusion}

This study carried out a horticultural therapy program for 110 minutes once a week every Wednesday on trainees entering the Juvenile Classification Review Center to determine the emotional effects from March 21 to September 21, 2018 with 16 female trainees of commissioned education at the Juvenile Classification Review Center in A city. We carried out the program to prevent redelinquency of juvenile delinquents and provide positive education, and examined changes in anxiety, self-esteem, self-efficacy and stress index that affect delinquency. The program was carried out in total four sessions, two on transplanting and two on flower arrangement, to fill the gap of positive education and prevent redelinquency during the four weeks of their stay in the center. The subjects were to arrange flowers and present their thoughts on topics such as "Expressing my mind" and "Why I am more beautiful than flowers" through flower arrangement, find their own strengths and explore themselves. They also transplanted the plant bodies on flower pots and gave presentations on "My most precious friend", expressed their own gardens and talked about the topic of "Who would you like to be with?" and those who had been with them so far, through which they explored themselves and people around them and reflected on themselves. Moreover, they were to take care of the plants they had transplanted during the time they were entrusted to the center.

As a result of examining the changes in the trainees of commissioned education entrusted to the Juvenile Classification Review Center after horticultural therapy, it was found that anxiety decreased after the program with a statistically significant difference $(p=.002)$. Self-esteem $(p=.420)$ and self-efficacy $(p=.178)$ increased slightly, but there was no statistically significant difference. However, stress index, which shows the physiological change of emotional functions, decreased after the program with statistically significant difference $(p<.001)$.

It was found that the horticultural therapy program prevents redelinquency and provides an opportunity for positive education by reducing high anxiety and stress of juvenile delinquents. The trainees of commissioned education who participated in the program showed a great interest in horticulture. This implies that other positive effects can also be expected from juvenile delinquents. Accordingly, we suggest further research on various horticultural therapy programs for juvenile delinquents with more samples, and expect to see continuous research to test the effectiveness of the horticultural therapy program on trainees of commissioned education.

\section{References}

Butcher, D.A. 2000. The relationships among engagement in youth development programs, risk and protective factors, and problem behaviors: An exploratory study. Doctoral dissertation, Utah University, Utah, USA.

Cha, J.E. 1997. A study of for development of a general self-efficacy scale. Master's thesis, Ewha Womans University, Seoul, Korea.

Choi, B.G. and G.Y. Jeon. 1993. A study on the development of the self-esteem inventory. J. Korean Home Econ. Assoc. 31(2):41-54.

Choi, J.S. and S.C. Cho. 1990. Assessment of anxiety in children: Reliability and validity of revised children's manifest anxiety scale. J. Korean Neuropsychiatr. Assoc. 29(3):691-702.

Choi, Y.W. 2012. The effect of horticultural therapy on 
female reformatory students to improve adolescent personality. Master's thesis, Korea University, Seoul, Korea.

Choi, Y.W., K.E. Lee, J.J. Ahn, E.J. Jang, and Y.J. Park. 2016. Analysis of satisfaction of personality education program and preference of plants and horticultural activity of reformatory students. J. Korean Soc. People Plants Environ. 19(2):101-113. https://doi.org/10.11628/ ksppe.2016.19.2.101

Choi, Y.W., S.W. Park, and Y.J. Park. 2014. The effect of horticultural therapy on improvement of self-esteem, immersion and happiness to female reformatory student. J. Korean Soc. People Plants Environ. 17(4):247-253. https://doi.org/10.11628/ksppe.2014.17.4.247

Han, H.J. 2002. The effects of self assertiveness training on the development of children's self-efficacy. Master's thesis, Seoul National University of Education, Seoul, Korea.

Han, Y.S. 2009. The effect of horticultural therapy on reformatory students' formation of ego-identity and emotional stability. Master's thesis, Jeju University, Jeju, Korea.

Hwang, S.H. 2012. The study on characteristics of juvenile delinquents by special personality inventory test-R. Master's thesis, Kyonggi University, Suwon, Korea.

Jang, E.M. 2006. The experience of juvenile delinquency in the juvenile protection and education institute: Focusing on the youth with juvenile delinquency experience in the JPEI in Gwang-ju. Master's thesis, Chosun University,
Gwangju, Korea.

Jin, H.J. and H.J. Kim. 2007. A study on improvement of educational function and education program in the juvenile classification review center. Korean Juv. Prot. Rev. 30(4):43-71.

KBS Special Production Team. 2009. The secret of flowers. Seoul, Korea: Gachichangjo.

Kim, E.H. 2013. The effect influencing on the impulsiveness and self-command power of female juvenile delinquents by the art therapy program. Master's thesis, Kwangju Women's University, Gwangju, Korea.

Lee, E.H. and S.M. Nam. 2002. Application of horticultural therapy to middle-school pupils. J. Korean Soc. Plants People Environ. 5(3):32-43.

Lee, E.Y. and Y.R. Tak. 2001. Gender difference in self-esteem, physical and mental health in adolescents. Child Health Nurs. Res. 7(4):474-482.

Lee, H.S. and J.H. Lim. 2015. Spss 22 manual. Seoul, Korea: Jyphunjae.

Noh, J.Y. 2016. The effects of horticultural therapy on reducing bullying, depressive feelings, anxiety and stress and promoting resilience for adjustment among teenagers. Master's thesis, University of Seoul, Seoul, Korea.

Son, M.R. 2015. Effect of horticultural therapy on school life adaptation and stress of juvenile. Doctoral dissertation, Wonkwang University, Iksan, Korea.

Song, S.J. 1996. Family and family therapy. Paju, Korea: Beopmunsa. 